\title{
First-year students' conflicts during their construction of an academic identity in English as a foreign language: Implementing Cultural-Historical Activity Theory
}

\author{
Angels Oliva-Girbau \\ Universitat Pompeu Fabra, Barcelona, Spain
}

(Article received 16 July 2011; final version received 30 September 2011)

\begin{abstract}
This paper constructs a theoretical framework that views academic writing from a context-based perspective. The shift from text to context results from implementing the concept of activity system into the academic community, envisioning academia as the sum of the interactions among its components (users, tools, goals and results), which was applied into an instrumental English course for first-year students through reflective activities that promoted awareness and discussion of the components of the academic community during students' initiation. We analyse the results of the first one of these activities, a questionnaire students answered as part of the class work. Their replies to this questionnaire show lack of awareness of the components of the academic activity system, one of the sources of the conflicts they experience during their initiation into the academy. Finally, we suggest a new approach to writing instruction that involves the convergence of research and instruction.
\end{abstract}

\section{Introduction}

Entering the academic world challenges first-year university students' identity in many ways, at an age when many of them are still struggling to define their adult persona. The recent implementation of the new degrees within the European Space for Higher Education, and the waves of protest on the part of students, have only increased students' awkward relationship to an ever-growing academic community that they perceive as alien, rigid and imposing. Changing the focus of instruction of an academic writing course from text to texts and contexts and adopting a model based on Cultural-Historical Activity Theory (CHAT) can enable students to become aware of the components that make up the academic community they are about to enter, the relations among them, and the socialisation process entailed.

By studying the interactions between these components, we explicitly articulate the ways in which academic identity is shaped, and therefore we can attempt to expose the conflicts that make it hard for first-year students to become part of the academic community and suggest some possible ways to help them. An approach based on CHAT views written genres as multifunctional tools that contribute to learning, assessment and identity-building in the specific contexts in which they 
operate. CHAT is rooted on the idea of practice as the path to act through discourse. The notion of activity, doing something to obtain a result, is in this framework intrinsically embedded in the socio-historical moment in which it occurs, thus connecting discourse to the tools through which it is realised, their users, the motivations that trigger it and its context. CHAT also takes into account the conflicts derived from the plasticity of the genres, roles and functions of these components within individual activity systems. Consequently, we consider this framework a suitable tool to 1) raise students' awareness of the changing and idiosyncratic nature of the academy and their potential role within it; 2) promote contestation of the power relations and assumptions underlying academic interaction; and 3) encourage active participation and engagement on the part of students and professors.

\section{Academic genres}

Academic writing, like all forms of communication, is an act of identity: it not only conveys disciplinary 'content' but also carries a representation of the writer (...) our discoursal choices align us with certain values and beliefs that support particular identities (Hyland, 2002:1092).

As a social activity, writing and learning to write in a new context requires people to adopt a multiplicity of roles in order to adapt to the different contexts in which they interact, which are defined by the outcomes of interactions in a variety of culturally-defined contexts, with a variety of people and purposes (Hyland, 2002; Shotter \& Gergen, 1989). As we adopt the discourse forms that prove successful in these situations, we internalise as well the practices and structures of the community we are entering, and its values. The process of negotiation between individual and collective values in social situations is not a process of total acculturation, but rather one of mutual influence, a process of “positioning” (Davies \& Harré, 1990; Fairclough, 1995) that can sometimes prove problematic when we enter radically different spheres of action. Each of us is constantly influenced by a multitude of discourses which are situated in the groups in which we participate and which mediate our involvement in any one of them. Most importantly, much of our sense of who we are originates in our home cultures. The fact that we bring this sense of self to our acts of writing in the university can create an acute sense of dislocation and uncertainty (Hyland, 2002: 1094).

By employing the tools of the community they want to join, new members are expected to inadvertently appropriate its collective goals and knowledge, and prove their contribution -and consequently their value- as members of this community. Academic socialisation, students' construction of an academic identity, requires first-year students to dramatically redefine their pragmatic competence in an altogether new form of literacy which is often associated to forms of 
discourse and values that feel alien to them. This process entails a variety of problems for first-year students, regardless of their mother tongue.

Every community develops a different set of tools or genres to suit its needs, hence establishing a mutually defining and ever-changing relationship between a community and its genres, so that its members bind their genres to a specific set of intentions, relations and circumstances (Bazerman, 1995). For non-native English speakers, academic literacy involves the extra challenge of having to undergo this process at least twice, as the practices of the different linguistic communities cannot be automatically transferred, even within the same discipline. Apart from the language-related issues they may find, they are hindered by their own rhetorical identities, which "may be shaped by very different traditions of literacy” (Hyland, 2002: 1091-1092) determined by often implicit cultural-specific issues. Even though individuals may belong to more than one community, or perceive similarities between the genres they use, genres cannot be successfully transferred across contexts because of their being so bound up to their specific context of use, to the extent that they signal an individual's belonging to a group or not:

Over a period of time individuals perceive homologies in circumstances that encourage them to see these as occasions for similar kinds of utterances. These typified utterances, often developing standardized formal features, appear as ready solutions to similar appearing problems. Eventually the genres sediment into forms so expected that readers are surprised or even uncooperative if a standard perception of the situation is not met by an utterance of the expected form. (Bazerman, 1995: 82)

Genres provide speakers with models of suitable responses to situations they are likely to encounter in their usual sphere of action. Consequently, "knowing the genre means knowing, not only, or even most of all, how to conform to generic conventions but also how to respond appropriately to a given situation” (Devitt, 1993: 577). Discourse and context are thus bound by a mutually defining relationship, as genres build and are built by recurrent situations (see figure 1.1 below), facilitating the increasingly complex communication needs of the members of discourse communities by inserting discourse functions into predictable structures. Bakhtin (1986) linked human activity to language, and as human activity is diverse, so are the forms in which language is realised. As human activities become increasingly complex and varied, the genres linked to them must necessarily become "changeable, flexible, and plastic” (Bakhtin, 1986: 80-81) in order to facilitate communication. The number of genres is potentially infinite "because the various possibilities of human activity are inexhaustible" (Devitt, 1996: 60), and infinitely specific "because each sphere of activity contains an entire repertoire of speech genres that differentiate and grow as the particular sphere develops and becomes more complex” (Devitt, 1996: 60). 


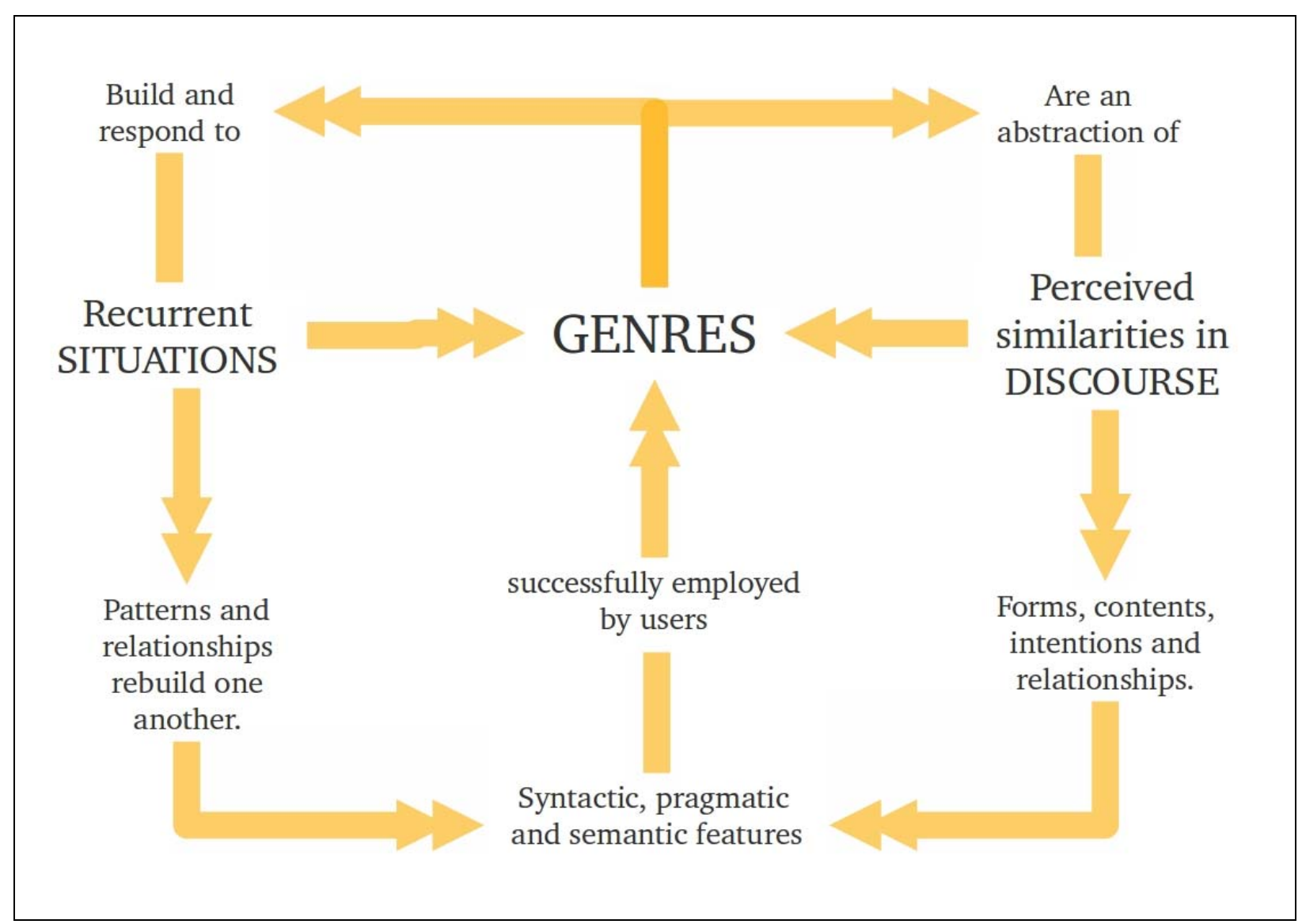

Figure 1: Discourse genres

Academic genres (AG) form a sub-group within discourse genres, with their own range of subgenres, in a never-ending fractal process of adaptation to different fields and institutions. AG are extremely dynamic (see figure 2), they are not universal, but determined by the context of their usage, constantly updated depending on the results obtained in the specific situations in which they are put to use - the language in which they are used, the status of the users, the discipline, and such.

The academic texts of a discipline are all intertwined, in the sense that the multiple voices of their writers construct the discipline's collective knowledge. Academic writers act as part of a discourse community (Mullin \& Wallace, 1994; Braüer, 2003); their commitment to a discipline involves their partaking of its collective goals in their contribution to the field (Rienecker \& Stray Jörgensen, 2003). Each text depends on the existence of many other texts, which themselves were written on the basis of former texts. Their recurrence and index of referentiality constitute marks of status and recognition in the author's relation to other members of the discipline. 
Developed within each discipline

ACADEMIC CONTEXTS

Writing as MEANING-

MAKING, as a

LEARNING TOOL, as a form of ASSESSMENT.
ACADEMIC GENRES

Knowledge of

CONCEPTS, FORMS and

RELATIONS
Evolve through

intertextuality

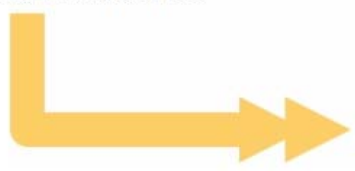

\section{Genres prove \\ BELONGING to the \\ group of EXPERTS}

Figure 2: Academic Genres

\section{Building an academic identity}

The identity of the academic writer is mutually dependant of the genres he/she employs and their impact. By displaying their knowledge of the forms, concepts and relations assigned to a certain genre, users reassert their identity as members of the group and contribute to its goals. This is a never-ending process of renegotiation of status, as "the rules of the game constantly change in response to a wide range of intellectual, material, and political forces within and outside the community” (Russell, 1991: 14). Within the same community of knowledge, a user's status is not stable, but fluctuating between expert and novice, as new genres emerge or change through time.

For first-year students, being able to learn academic writing and the genres that represent it in the specific context of each discipline, department and such determines their results at university and their professional options after their graduation. AGs are students' key to their permanence at university and for their long-term learning throughout the degree, post-graduate studies and further into their professional life. In order to become part of the expert community, novice writers need to prove their acquisition of the knowledge shared by the community and employ the specific genres of this field. Throughout the process of acquiring AGs, students are actually acquiring not only 
essential knowledge or expertise in their field, but also the means of becoming members of the expert community. This process of initiation can be problematic for all students, regardless of their linguistic background, as academic ways can sometimes contradict discourse practices that identify them as part of their home community, and therefore challenge their values and identity.

For non-native speakers (NNS), the acquisition of academic discourse in English feels doubly foreign. Their contribution to collective knowledge, and hence their value within the academic community, is undermined by their image as poor producers of academic discourse in the language of prestige (Modiano, 1999; Matsuda, 2003). Büker (2003) classified into four categories students' conflicts when writing academic papers in a foreign language: the content-specific level, the domain-specific procedural level, the level of cultural coinage, and the foreign language proficiency level. These levels are not clear-cut, but rather overlap one another and affect different functions. Their first problem, the content-specific conflict, concerns subject knowledge, as firstyear students feel extremely inexperienced regarding the knowledge of their discipline. Fieldspecific procedural knowledge covers the generic conventions that characterise academic writing the right subject matter, register, etc. It refers to students' need to employ the procedures typical of the field, even if they have not had any specific instruction on them. These two problems concern students' acquisition of the background knowledge shared by the interpretive community (Fish, 1980), the readers and writers of any specific field of knowledge. In order to be recognised as part of this interpretive community, the authors and writers of academic texts are expected to write according to field-specific substantive and procedural features, thus signalling that their text belongs in their field.

The next two levels of conflict are specific to NNS learners of English for academic purposes. Regarding the problems derived from cultural coinage, the conventions of particular academic communities are strongly influenced by their different traditions (see Rienecker \& Stray Jörgensen, 2003). Such cultural differences affect both the focus and the form of the AG their members write in, and do not solely depend on the language. As for the problem of foreign language proficiency, Kruse (2003) argued that the school-to-university transition already hinders their communicative capacity because of its unfamiliarity to students' usual linguistic repertoire. The main issue regarding foreign language proficiency is that the students' linguistic knowledge interferes with students' success because it masks their difficulties at other levels. Students writing in L2 often feel concerned that using a foreign language will undermine their explication of content: They tend to see their lack of competence in L2 as the only source of their problems in writing, disregarding the cultural, discipline-specific and procedural problems they may have. The multiplicity of purposes, contexts and methods associated to acts of communication makes it 
necessary to find a unit of study larger than genre to understand the mechanics of discourse communities.

The Cultural-Historical Activity theory (CHAT) reconceptualised the Bakhtinian notion of discourse as a process of dynamic negotiation between users, in which genres mediate interactions between speakers so that discourse and context become one (Russell \& Yáñez, 2003). Genres are not simply texts that share a set of formal features that translate into functions, but the intervening steps between a community and its long-term goals, and a way for users to identify themselves and others. Along these lines, Russell and Yáñez suggest that CHAT is:

Una teoría dialéctica amplia que incluya los objetos y motivos de los colectivos y sus participantes, así como también sus interacciones recíprocas entre las mentes y los textos en la interpretación de los lenguajes sociales. (2003: 70)

The solution to the limitations of genre theory is based on the activity theory developed by Cole and Engeström (1993) out of Vygotsky (1978) and Leontev's (1978, 1981) work, which replaced the diaological metaphor of context and discourse with a conceptualisation of context as a network of dynamic systems that are made up of human agents, tools and discourse, offering the activity system as the new basic unit of analysis. Activity systems (AS) are made up by groups of people who need to carry out some specific actions in order to achieve a common goal. Faced with a problem to be solved, they pick some means of action, some tools to deploy. If their choice leads to success, they may use the same action in the future, until these tools become operationalised. Using AS, we can analyse the way in which specific tools are implemented to mediate the goals and the object (focus or problem) of a community, and how they change over time in relation to the subjects, either individuals or groups, who work towards some results, while their participation in different AS contributes to build their social identity.

From a social perspective, the acquisition of genres entails one's engagement with the identity and goals of the system. Newcomers acquire genres by trial-and-error as they participate in the exchanges of their AS. They imitate what they perceive to be tools and forms of use, and internalise them if they perceive that they are successful employing them. As the acquisition of genres occurs dialectically, there are tensions and conflicts between the different objects, goals tools and subjects of the multiple AS learners operate in when they attempt to transfer genres across different subjects, institutions, departments, and such (Russell \& Yáñez, 2003).

As new users acquire genres, they also internalise the object/motive of the activity and the identity of the group. In the academic context, by making explicit to students the mechanics of the community they intend to join through the study of its specific discourse patterns and their own development as members of it, we turn writing instruction into a tool of inclusion that grants first- 
year students prompt access to their field of knowledge as learners and active participants, challenging the power hierarchy of the academic AS. For novice writers, academic identity is defined by their learner status and their perception of themselves within the AS of higher education. Their conceptualisation as academic writers depends on the relationship they perceive they have or may potentially have with the goals, tools and users of the system. For learners initiated into multilingual contexts, the number of genres multiplies, and so do the conflicts between them.

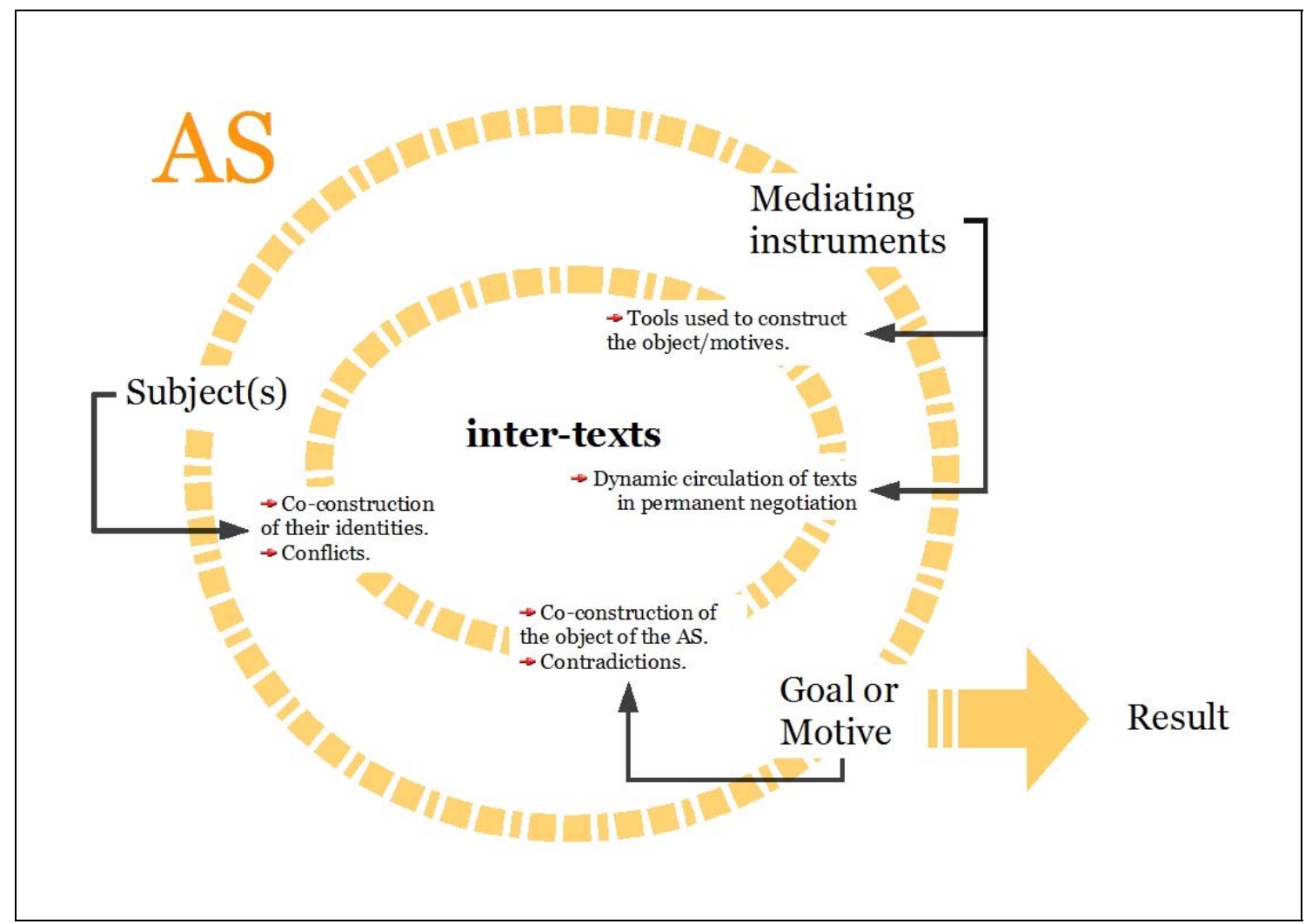

Figure 3: Interaction of the components of the AAS

\section{Research Methodology}

In order to promote students' awareness and discussion of the components of the AAS, we devised a series of reflective activities to be carried out every week in the class or online, and based on the ideas of CHAT about the academy as an activity system. In this paper, we analyse the outcome of the first one of these activities, a questionnaire about students' initial perceptions of the academic AS and its components. On the day of the first seminar, students discussed their answers to this questionnaire in small groups, contributed to a whole-group discussion of the Humanities as an AS and then filled in the questionnaires individually or in groups of two or three.

The questions touched on the following topics: Students' conception of the AG (questions 1, 2, 3 and 4); students' perceptions on the process of becoming part of the AAS (questions 5, 6 and 7); 
and students' perceptions on the roles of AG in the AAS (questions 8, 9 and 10). The questions were kept open and simply-worded to ensure students' spontaneity. Students were allowed 20 minutes to fill in the questionnaire in class, either individually or in pairs/small groups. The professors emphasised that this was not a graded test, but a tool to measure their progress at the end of the term. In total, we gathered 50 questionnaires, written in English and Catalan. For the sake of analysis, we translated the ones students wrote in their L1, and corrected the spelling of the ones written in English. The table below displays the list of questions under their headings:

Table 1: Questions

Topic: students' conception of AG

\begin{tabular}{l|l}
\hline 1 & Five words that describe academic writing. \\
\hline 2 & The format of academic writing is... \\
\hline 3 & The most important thing about academic writing is... \\
\hline 4 & In comparison to writing in my mother tongue, writing in English feels more... and \\
\hline
\end{tabular}

Topic: students' perceptions of the process of becoming part of the AAS

\begin{tabular}{c|l}
\hline 5 & As a member of the Humanities, I feel... \\
\hline 6 & Learning to write in the academic community means... \\
\hline 7 & My relation to other members of the Humanities is... \\
\hline \multicolumn{2}{|c}{ Topic: students' perceptions of the role of genres in AAS } \\
\hline 8 & Academic writing is used in university to... \\
\hline 9 & The target audience for academic papers is... \\
\hline 10 & When I write academic essays, I intend to...
\end{tabular}

The sample for our case study consisted of 204 first-year students of the subject Llengua Anglesa per les Humanitats at Universitat Pompeu Fabra, divided into ten seminar groups. Llengua Anglesa per les Humanitats has been a compulsory first-year subject for all Humanities students since the implementation of the new degree. It replaces a year-long course on foreign language and literature in which students could choose among English, French and German. With the new plan, all students need to take Llengua Anglesa per les Humanitats (LAH) during their first year of studies, and they can later on enroll in the German or French equivalent as an option. Whereas the focus of the French and German subjects is placed upon enriching students' knowledge of the culture and literature associated to these languages, LAH is intended to provide students with instrumental generic know-how in English for academic purposes, therefore becoming a so-to-speak contentless subject that aims at being an introduction to English for academic purposes, 


\section{Results}

Regarding students' conception of AG, the first question required students to list five words that summed up academic writing for them. Students' description of academic writing is very formfocused, as we see in the visualisation of the answers to question 1 . The most widely used words are formal, vocabulary, structure, specific, cohesion and coherence. Close to these, we find technical, ideas, register and clear. Negative words such as hard, difficult, strict, bored, stressful or impersonal have very few occurrences. Grammatical aspects also occur rarely (grammar, connectors, contractions, rhetorical, verbs, mistakes, adverbs).

The answers to question two correspond to students' perceptions of academic writing in question one. They emphasize the formality of the textual aspects of AG (formal, clear, register), with references to the genres they associate to the academic community (essays, letters, articles, newspaper, speeches), and specific sections of the essay genre (paragraphs, introduction, conclusion, discussion). Therefore, students either connected format to genre, or to register and structure. The formality of the academic register feels alien to them, it is something strict, organized, structured or well-structured, something out of their reach that "we need to learn”, "more formal than other kinds of essays".

Question three, which complements the opening question, requested students to name the key aspect of academic discourse. Students' answers tended to focus on the structural aspects of AG, both regarding textual organisation (coherence, cohesion, organise) and issues of accuracy (language, form/formal, correct, register). However, we can also find attention to the communication of contents and audience interaction, with prominent words such as ideas, information and clear, and to a lesser extent, topic, opinion, express/expressing, message, convey, plagiarism and understand.

In the last question describing students' conception of AG, students were asked to compare their perceptions of their own writing in L1 to their writing in EIL. Some students argued that they had little experience writing in English, and not much writing academically in general. Their answers reflect their awkwardness and alienation regarding AG in English: difficult, insecure, unconfident, complicated. There are a few references to formal aspects: grammar, fluent, colloquial, words, and hardly any mention of English being international, cosmopolitan or communicative.

Questions five, six and seven displayed students' perceptions on the process of becoming part of the AAS. Remarkably, many students connected question five, their feelings as members of the Humanities, to international language issues and the importance of using English in the academic community in terms of contents and opportunities (English, important, educated, language, necessary, learn/learning, academic). Academic writing in English is perceived as a 
necessity for their future in the academy, something they need for "reading texts, working with them", "an important matter we have to know to understand the subjects", bound to their academic life since "knowing how to write academic writing or how to interpret it is really important for the development of my degree and my ability as a student”, but also connected to their professional career because "English opens many doors". We can also find specific references to the disciplines (literature, history, philosophy) and some positive phrasing regarding students' attitudes towards these (interested/interesting).

Students' answers to question six show a more open focus regarding their acquisition of AG. Whereas the most widely used word still referred to the formal aspects of AG (vocabulary), we can also find terms connected to their goals within the AAS (future, ideas, possibility, express, know, communicate, professional) and its users (people, community). Writing is seen as a "fundamental skill to express ideas, opinions and theories", a tool that "is very important for my future". Although many of the references to the process of acquisition referred to language-related issues (vocabulary, grammatical rules, correctly, etc), there are also references to the relationship established with the audience and the contents through the written word ("so people understand me", "relationships with other people", "to communicate better", "being able to share my ideas in the academic community").

Question seven presents students' views of their relation to other members of the Humanities. Most students viewed their classmates as the only other members of the Humanities, and defined their relationship with them as good or interesting, describing them as friends, classmates, people they share interests with, who are interested in the same areas, who can help each other. Solidarity and companionship are highlighted as the bases for their good relationship, which is also perceived positively because they partake an interest in the same field and they can learn from each other ("cooperative, everybody must participate in the different processes to get and share information”). Even though these features may apply to their professors as well, we do not find a single mention of them in students' responses.

The topic of the last three questions was students' perceptions of the role of genres in the $A A S$. In question number eight, the function of academic writing was mainly assigned to the writing of essays - although they also mention exams, texts and project - with a focus on accuracy (properly, improve). Students referred to some of the functions of academic writing at university. Writing was an assessment tool, a test "to pass subjects", a learning tool to acquire "new knowledge of the degree", and a proof of status to show their knowledge. Some students also viewed academic texts as a way to "communicate them to the rest of the academic community" and an aid to "convey knowledge". 
According to their replies to question nine, these texts are addressed to expert educated people from the community, professor/s, their teachers, other students, professionals, specialists. The audience of their writing are people who know, who are interested in and partake of their knowledge of the specific topics. They perceive that these texts are not suitable for everyone ("not everybody can read such specific papers”, “people who really know what you're writing about”). In this case, unlike in previous questions, teachers do appear to be part of the knowledge community: "educated people like teachers", "they usually know more than you about the ideas which you expose in it”.

In spite of their focus on form in the previous answers, their goal when writing, as stated in question ten, seems to be directed at conveying their ideas, albeit in a clear, formal, coherent, correct way. Students seem to be very concerned about the transparency of their communication, they want to be understood, and to convince their readers. Their will to communicate (express, transmit), however, needs to overcome some obstacle, hinted at by possible, careful, try, mistakes. These obstacles seem to bring back the focus on the formal aspects of AG (words, arguments, structure, easy, rules, simple) and the foreign language problem ("use English as correctly as I can", "transmit the same thoughts that I transmit in my mother tongue”).

\section{Discussion}

We can infer from students' answers that even during the third term of their first year, and after having gone through an instrumental course on academic discourse in their L1, 1) some students still do not have a clear picture of the basic components of the academic activity system they are attempting to enter; 2) some students feel very insecure about their own identity as members of the academic system; 3) they blame this feeling on AG in English, which they think undermine their participation in the AAS.

Students view AG as text types defined by a series of formal aspects. They perceive this form as complex and alien to their own forms of communication, mainly due to the level of formality that these genres require from them and the rigidity of their structure in the AngloAmerican tradition. They are aware of their novice status, they do not feel they have internalized the tools of the system, and as a consequence they cannot identify their goals and their audience clearly when they write. However, and regardless of their problems with AG in their L1, students still assume this is due to the foreign language problem. English seems to obstruct their ability to communicate clearly and efficiently, it undermines their capacity to be coherent and articulate, to make themselves understood. It is not that they lack things to say, but rather that they cannot convey them properly. We found in students' responses a clear perception of AG as the tools to 
communicate within the academy, only that this communication does not occur smoothly on their side, either as receivers or as producers.

Having to learn AG in a foreign language is a source of conflicting thoughts for many of the students. On the one hand, they feel that English is important for their future careers, and for their progress at an international level. Reading and writing in English is necessary to learn and to participate in the knowledge community. They envision the multiplicity of functions written discourse performs in the AAS, but they do not feel they have been granted access to some of them. Students feel they are being put to the test, both in terms of form and contents, they do not see themselves as participating of the collective construction of knowledge. Their high level of engagement to their studies conflicts with the barrier set up by AG in English between them and the contents of the disciplines they want to join, both as receivers and as producers, which triggers anxiety about their role and their image within the AAS.

Their conceptualisation of the knowledge community is not quite defined yet, probably due to the complexity of the tools to relate to them. The most immediate relationship they identify is with their peers, with whom they establish a relationship of mutual help and support, whereas professors and experts are people they can only relate to through texts, ergo inefficiently. Still, students see that writing can bring them closer to the expert community because it is the key to participating of the idea exchange and the social construction of knowledge. They are eager to communicate their ideas about the field so that they can be validated by the expert audience, of which themselves and their peers cannot be part. Such deficiencies in their communication skills cause them to perceive that they are sending out the wrong picture of themselves because of their lack in language skills. Their identity is therefore damaged by their lack of expertise in AG. They believe that they have the contents right - even though they still have a lot to learn -the only problem they perceive is that they cannot communicate these properly because of their problems with genres in English, on which they pin the conflicts they experience with the ideational, structural and interpersonal problems within the AAS.

\section{Conclusions}

Students' problems with the acquisition of AG should not be regarded from a purely textual point of view, as they are embedded in the conflicts derived from their process of initiation into the AAS. Therefore, students' construction of their identity as members of the academic field is mutually dependent on their relationship to the novice and expert members of the academy, its contents and goals, and the tools used to interact, mark status, initiate new members and negotiate the goals of the AAS. 
Regarding writing instruction, AG are so inextricably bound to their context of use, their users and their goals, it is impossible to learn/teach them separately. In order for students to acquire and successfully employ AG, we need to move beyond a merely textual view on AG when designing writing instruction. By explicitly teaching students the relationship between genres and the key components of their context of occurrence, we can help first-year students become aware of how this relationship determines their own academic identity and their interactions with the other members of the community as they contribute to the goals of the discipline. Because of its broader perspective on communication, CHAT can provide us with a powerful framework to analyse the conflicts novice writers experience when being socialised into the AAS, as it takes into account all the elements in it, and not just genres.

Our goal as writing instructors in higher education should not stop at teaching students to use a certain range of AG, but to help them to use them to make meaningful contributions to the community, partake of its goals and interact with other members of it. In combining genre theory with Cole and Engeström's activity theory, CHAT binds together genre and activity systems, regarding written texts as tools that mediate the interaction of individuals with groups in order to build up temporarily stable structures of action and identity. Situated in context, we can analyse the genres through which academic identity is realised, and the ways in which these genres help construct and negotiate goals, users and the community itself.

\section{References}

Bakhtin, M. M. (1986). Speech genres and other late essays. Austin, Texas: University of Texas Press.

Bazerman, C. (1995). Systems of genre and the enactment of social intentions. In A. Freedman and P. Medway (Eds.), Genre and the new rhetoric (pp. 79-101). London: Taylor \& Francis.

Braüer, G. (2003). Centres for writing and reading - bridging the gap between university and school education. In L.Björk, G. Braüer, L. Rienecker, \& P. Stray Jörgensen (Eds.) Teaching academic writing in European higher education (pp.135-150). Dordrecht: Kluwer Academic Publishers.

Büker, S. (2003). Teaching academic writing to international students: individual tutoring as a supplement to workshops. In L.Björk, G. Braüer, L. Rienecker, \& P. Stray Jörgensen (Eds.) Teaching academic writing in European higher education (pp.41-58). Dordrecht: Kluwer Academic Publishers.

Cole, M., \& Engestrom, Y. (1993). A cultural historical approach to distributed cognition. In G. Salomon, (Ed.) Distributed cognitions (pp. 1-46). Cambridge: Cambridge University Press.

Davies, B., \& Harré, R. (1990). Positioning: the discursive production of selves. Journal for the Theory of Social Behaviour, 20 (1):43-63.

Devitt, A. (1993). Generalizing about genre: new conceptions of an old concept. College Composition and Communication, 44: 573-86.

Devitt, A. (1996). Genre, genres and the teaching of genre. College Composition and Communication, 47: 605-615. 
Engeström, Y. (1995). Expansive learning at work: toward an activity theoretical reconceptualization. Journal of Education and Work, 14: 1: 133-156 .

Fairclough, N. (1995). Critical discourse analysis. Boston: Addison Wesley.

Fish, S. (1980). How to recognize a poem when you see one. Is there a text in this class? The authority of interpretive communities. Cambridge, MA: Harvard University Press.

Hyland, K. (2002). Authority and invisibility: authorial identity in academic writing. Journal of Pragmatics, 34(8):1091-1112.

Kruse, O. (2003). Getting started: academic writing in the first year of a university education. In L.Björk, G. Braüer, L. Rienecker, \& P. Stray Jörgensen (Eds.) Teaching Academic Writing in European Higher Education (pp. 19-28). Dordrecht: Kluwer Academic Publishers.

Matsuda, P. (2003). Proud to be a nonnative English speaker. TESOL Matters, 13(4):15.

Modiano, M. (1999). International English in the global village. English Today, 15(2): 22-8.

Mullin, J.A., \& Wallace, R. (Eds.) (1994). Intersections: Theory-practice in the writing center. Urbana, Illinois: National Council of Teachers of English.

Rienecker, L., \& Stray Jorgensen, P. (2003). The (im)possibilities in teaching university writing in the Anglo-American tradition when dealing with continental student writers. In L.Björk, G. Braüer, L. Rienecker, \& P. Stray Jörgensen (Eds.) Teaching Academic Writing in European Higher Education, (pp.101-112). Dordrecht: Kluwer Academic Publishers.

Russell, D. (1991). Writing in the academic disciplines, 1870-1990: a curricular history. Illinois: Southern Illinois University Press.

Russell, D., \& Yáñez, A. (2003). Teoría de la actividad histórico-cultural vygotskiana y la teoría del sistema de géneros: Una síntesis sobre la escritura en la educación formal y la escritura en otras prácticas sociales. Entre Lenguas, 8:67-82.

Shotter, J., \& Gergen, K.J. (1989) (Eds.) Texts of identity. Newbury: Sage Publications.

\footnotetext{
Author References:

Angels Oliva-Girbau has been a professor at Pompeu Fabra University (UPF) since the academic year 2005-6, where she teaches courses in English literature and basic English instrumental for Humanities, Advertising and Public Relations degrees, in virtual courses and summer English for business. She also coordinated the practicum in the High School Teacher Education Master, and has participated in several projects to develop classroom materials. Besides her work at the UPF, she has also worked as a teacher in Content Language and Integrated Learning (CLIL) contexts and language immersion in English in high school, and teacher training. At this time, she is preparing her doctoral thesis at the Faculty of Education of the Universitat Autònoma de Barcelona, in the program of Language and Literature Education.

Email: angels.oliva@upf.edu
} 